\title{
Implementation of design for six sigma methodology on the car bumper production process
}

\section{Âli Yurdun Orbak}

Engineering Faculty,

Industrial Engineering Department,

Bursa Uludağ University,

Görükle, 16059, Bursa, Turkey

Email: orbak@uludag.edu.tr

\begin{abstract}
Competition increases daily in any market; therefore, continuous improvement of product or service is an essential tool for survival and making an impact on the industry. Companies that have successfully implemented the six sigma method have gained the most from incorporating their design for six sigma (DFSS) programs into their production processes. The primary purpose of DFSS is to "design it right the first time" to avoid negative experiences in the production flow. In this study, the parameters involved in the design of a selected passenger-vehicle bumper are optimised in the process of commissioning a new product using the DFSS method. The DFSS method is discussed on the first two steps of implementation of the "define, measure, analyse, design, verify" (DMADV) protocol. By additionally implementing the house of quality (QFD) and failure mode and effects analysis (FMEA) approaches, a vehicle bumper that will meet the maximum level of customer requirements is produced.
\end{abstract}

Keywords: DFSS; design for six sigma; house of quality; FMEA; failure mode and effects analysis; bumper production process; experimental design; factorial design; injection process; cause and effect diagram.

Reference to this paper should be made as follows: Orbak, Â.Y. (2021) 'Implementation of design for six sigma methodology on the car bumper production process', Int. J. Vehicle Design, Vol. 85, No. 1, pp.69-96.

Biographical notes: Âli Yurdun Orbak is currently a full-time Associate Professor in the Industrial Engineering Department of the Engineering Faculty at Bursa Uludag University. He has more than 50 publications in the fields of robotics, system dynamics and control, six sigma, quality control and management, and lean manufacturing. He is a Member of the American Society of Mechanical Engineers (ASME), a member of the Institute of Electrical and Electronics Engineers (IEEE), and a full member of the Sigma Xi Honorary Society.

\section{Introduction}

How can we make a customer more competitive? This study uses several tools and prior knowledge to design an error-proof bumper. Specifically, the house of quality (QFD) and failure mode and effects analysis (FMEA) are conducted to achieve the desired quality 
and performance level, and also to decrease the number of failures in ppm. Additionally, to optimise the design parameters, the design for six sigma (DFSS) method is commissioned together with the design of experiments method. In the bumper production process, many processes are present, and especially the injection process usually contains lots of errors (Beyenea et al., 2014). In this study, injection, paint, and assembly processes - the most critical processes of bumper production-were first examined, and studies related to these processes were conducted to create a new process design according to customer expectations. These three processes, and especially the injection process, also contain the most errors during the production of bumpers (Beyenea et al., 2014).

As the study was conducted in the automotive industry, the process of commissioning a new product was examined in detail, and the results of the study were actually applied. Because the bumper is not only a functional part of a vehicle but is also a visual product, product failure levels must be low. The study aimed to increase the value of the product to be produced by correctly determining customer expectations using detailed analyses of the study data and implementing measures suggested for changing the production process to achieve better customer satisfaction and make the company more competitive among its rivals. The contribution of the study to the literature includes information on implementing the DFSS methodology, experimental design, QFD, and FMEA methods in the process of commissioning a new product in the automotive industry, examining the steps in the process and how they affect the results, and applying the same improvement logic to different processes. Although most of the methods explained here have been used altogether or individually in the industry for many years, an interconnected logical application is usually missed. This paper fills this gap. Here, the methods are explained briefly for completeness.

The DFSS is an approach to adapt the process improvement concept of six sigma to the design of processes that bring them to the market with new products and services to meet the needs of the customer. It is effective in designing new products and services as well as redesigning the existing processes at the point where they lost their functions.

The first formation of the DFSS is realised with the concept of 'Customer's Voice'. It is necessary to analyse and identify potential customers in detail. The basis of the DFSS is the transformation of the expectations and requirements of customers about the product/service into the expectation of the process and the idea of making the process error-free.

The goal of DFSS methodology is to reach minimum defect rates, increase the current sigma level, or obtain a six-sigma level and maximise positive influence during the development stage of the new or improved products. For maximum performance, it is usually preferred to develop new products or services with six-sigma criteria. During this process, capability and performance also improve. Throughout its implementation, DFSS exploits many quality-oriented tools and techniques to meet most of the customer requirements (Kwak and Anbari, 2006). A high-quality level is ensured from the start by the determination and understanding of the wishes and requirements of the customers before the design phase. In this study, DFSS is chosen to be the leading philosophy to reduce failures during the manufacturing process.

The quality function deployment (QFD) method was first created by Akao (1997) in 1966 and further developed in 1967. Quality tables prepared by Dr. Mizuno and Dr. Furukawa provide information on systemising real quality (customer expectations) using 
functions and correlation of those functions with quality characteristics. These applications are considered to be the first examples of the QFD method in the literature. The QFD method was first used in the automotive sector in 1975 at Hino Motors (Toyota Group) and Toyota Auto Body. It was first used in the service industry by the companies Ohfuji, Noda, and Ogino in 1981 (Mazur, 1993). In Turkey, the Research and Development Centre (RDC) of Arçelik first used the QFD method for a dishwasher in 1994 (Ardıç et al., 2008). Bergquist and Abeysekera (1996) conducted a study using the QFD method in the process of developing ergonomic products and studied the characteristics necessary for producing shoes that were safe to be worn in cold weather. Sohn (1999) applied the QFD method to reduce the number of traffic accidents and identified the priorities in the control policies used in each police station.

Fan et al. (2017) applied the QFD method based on axiomatic design to a company that produces machine-made sand. Popoff and Millet (2017) used restricted satisfiability problems and the QFD in a sustainable life cycle design. Liu and Cheng (2016) developed a grey QFD approach using the grey TRIZ technique. The grey QFD method helps product developers define significant engineering characteristics and provides suggestions for possible improvements to those characteristics. In addition, a new grey sort method was developed for the sort range of grey digit ranges. Yang et al. (2018) proposed a new QFD-based model for risk management in transporting dangerous goods. This model was applied to improve the quality of transport services in a company in China that transports dangerous goods. In this model, the risk factors were identified, and measures to control those risks were defined in the processes used for transporting dangerous goods. The study results predicted that the new model provides significant support to experts in the effective decision-making process. Chin et al. (2019) used the QFD method in the field of high speed-train transportation in China. The criteria used to design a new internal cab improve transport quality and increase customer satisfaction. Govers (2001) examined examples of using the QFD method and their results in Japan and the Western world. The study observed problems in QFD applications and divided them into three categories based on methods, organisation, and product policy. The main idea behind the study was that the QFD method should be a management style rather than a tool and that this can be achieved only through cultural change.

Asadabadi (2017) created a customer-oriented supplier selection method that was formed by integrating the analytical network process with the QFD method and Markov chain. The changes and priorities of customer needs were tracked using the Markov chain, and a model was created. The analytical network process and the QFD method incorporated this model into product requirements and supplier qualities, which then created a supplier-selection method that focused on the customer.

Wang (2017) adapted the QFD-based platform to provide more distinctive marketing requirements and technical qualities of smartphones. The QFD method was integrated with TRIZ, and innovative alternatives were developed to resolve engineering problems. In this study, the QFD is used with 25 customer expectations which were associated with 25 quality characteristics. After the analysis, only three characteristics, namely, primer, paint, and varnish stayed, and as a result, paint was chosen for the most critical quality characteristic.

The U.S. Army developed the FMEA method that was first applied as a Military Procedure (MIL-STD) 1629 on November 9, 1949, and issued as Procedures for Performing a Failure Mode, Effects and Criticality Analysis. The FMEA was used by the U.S. National Aeronautics and Space Administration (NASA) between 1960 and 1965 in 
the moon-exploration program. It was implemented by the U.S. aircraft industry between 1970 and 1975 and was adopted as a general standard by Chrysler, Ford, and General Motors in 1988. The FMEA became compulsory within the scope of QS 9000, ISO/TS 16949, ISO 9001:2000, and other quality management and certification systems. Gilchrist (1993) proposed an FMEA model that included a cost analysis. Vandenbrande (1998) conducted studies to evaluate environmental risks. Setiawan et al. (2017) used the FMEA management method to analyse and determine risk-prevention priorities in the production process of the hollow core layer. Lijesh et al. (2016) conducted an FMEA study in which they determined various possible failure modes of different configurations of fixed magnetic bearings and the effects of these failures on the bearings. Guo et al. (2017) used the QFD and FMEA to research the importance of the parts used in shaft installation.

Peeters et al. (2018) designed a maintenance program for use in manufacturing additives for metal printing. Both the FMEA and fault tree analysis (FTA) methods in a repetitive structure were used to design the program. First, the FTA was conducted at the system level, and a set of failure effects was identified. The FMEA was then implemented to determine the critical failure modes. One function level of the FTA was studied for each failure mode, after which the FMEA was applied. Finally, the components were studied using both FTA and FMEA. Applying both methods provided more effective and useful results within a shorter timeframe. Kim et al. (2019) compared the use of the FMEA and evaluated the results in only the workflow of magnetic resonance (MR) (i.e., the implementation of MR simulation as a primary planning method) used in pelvis therapy with a conventional multiple-model workflow. Liu et al. (2018) conducted an FMEA study on the safety of the supply chain at gas stations in China. In the entire operation process of the gas station, data were analysed using the FMEA and the entropy weighted method. The study found that the most common accidents in this industry were bursts of static electricity. This result developed awareness among all the personnel who were related to the operations for the areas with a high possibility of explosion and provided methods by which future accidents could be prevented, thus preventing potential damage to the environment.

Yang et al. (2018) conducted an FMEA study to provide a new and more powerful solution to the problems with the heating, ventilating, and air conditioning systems (HVAC) in buildings. To conduct the FMEA using the proposed method, work orders were collected from 44 building clusters in Canada to create a dataset, and those work orders related to an HVAC system, and its components were studied. The results indicated that the FMEA provided a useful tool by which signs of HVAC failures in building operations could be analysed and isolated. In this study, the FMEA study was applied to all related processes, beginning with the one having the highest weighted value in the house of quality application. A total of 55 failure modes were investigated.

Experimental design is a technique used to determine variable values that affect process performance by systematically changing the values of controllable variables that affect the quality characteristics of the process (Montgomery, 2013). Experimental design applications have been used by Ronald Fisher in the agricultural sector since 1920. In the agricultural industry, different fertiliser types and doses are used to determine the effects of climatic conditions and irrigation levels on various products. The idea of increasing the quality of production was first developed in Japan between 1951 and 1970, then it was noticed by the USA and other countries; statistical methods and especially experimental design studies were increased to improve the quality of production. In the years from 1971 to 1990 , significant improvements were made, especially in the field of quality 
control. In this process, Total Quality Management and Continuous Quality Development methods, etc. were examined, and Taguchi robust parameter designs and process robustness concepts were introduced into the literature. After 1990, economic developments and competition accelerated, and this led to the development of statistical methods. The aim of all disciplines is to investigate and increase efficiency and effectiveness; therefore, experimental design studies have to be done.

Experimental design method is still used in optimisation and decision making in various fields. Bahloul et al. (2006) used the response surface method to minimise the force applied by the tools in the bending process and minimise the maximum tension. Dixon et al. (2006) used the experimental design method in the production of medical devices. Rojas et al. (2007) used a dynamic system-defined minimum-maximum robust experimental design method. Anawa and Olabi (2008) used the Taguchi method as an experimental design method to determine the necessary welding parameters related to the specified fusion cutting. Cheng et al. (2008) used the dynamic model of the Taguchi method, which includes the idea of optimisation of process parameters to minimise the thickness deviation value of the sub-layer sedimentary silicon film of different sizes. Oudjene and Ben-Ayed (2008) used the Taguchi experimental design method to analyse the effects of tool geometry on the shape with common resistance to riveting. Rosa et al. (2009) used the L16 Taguchi method for copper electrodeposition in titanium cables. Savaşkan et al. (2004) analysed fine hard ceramic coated (TiAlN and TiN) drill bits for the purpose of performance optimisation to achieve the optimum point, coating type, cutting, and feed rate parameter effects using the Taguchi Experimental Design method. Other researchers used the Taguchi method to improve the airspace error number of a motor and its share in total production volume (Akman and Özkan, 2011). In this study, the most widely used designs of $2^{\mathrm{k}}$ experimental design is applied to all three processes injection, paint, and assembly- to identify potential problems.

In the next sections, first application of the abovementioned logic sequence of QFD $\rightarrow$ FMEA $\rightarrow$ Experimental Design under the philosophy of DFSS is given. All calculations are presented with real values, but some of them are omitted because of privacy. Later, the results and conclusions are given together along with relevant discussions.

\section{QFD, FMEA, and experimental design application under DFSS}

In this section, the application of the QFD, FMEA, and Experimental Design is provided. Sustainability of the success of all the companies that produce products and/or services is directly related to the production at the right time and low cost. Since improvements in design provide significant improvements in product cost, studies should be directed to the correct logic for the first time. Companies gain significant gains with the DFSS applications. A customer-oriented design requires a process according to the customer's wishes. Designing is a challenging process that involves designing, analysing, and the steps of selecting and choosing the most appropriate design process.

In this respect, the proposed DFSS method is shown in Figure 1.

The DFSS method targets both types of design vulnerability according to the concept of designing the right one for the first time. This objective can be achieved by extended DFSS propagation, including asset design and developmental processes (Yang and El- 
Haik, 2003). There are a lot of different DFSS models, and one of them is define, measure, analyse, design, verify (DMADV), which is used in this study.

Figure 1 DFSS approach in different design phases

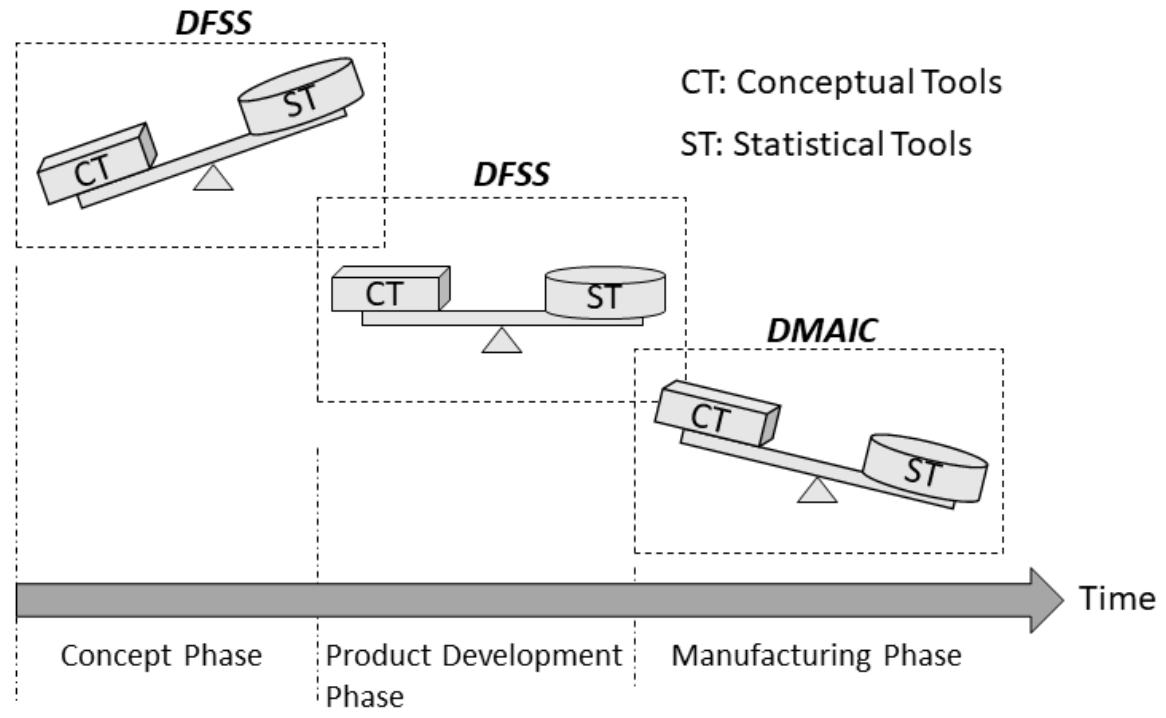

Source: Yang and El-Haik (2003)

The DMADV procedural strategy is very suitable for the development of follow-up products and elaboration of entirely new products or processes. The application of the DMADV starts with the Define phase, which contains business case, project planning, and scoping. In the Measure phase, transformation into specific and measurable customer requirements, deriving target values and tolerances are explored by analysing customer requirements. In the Analyse phase, the development of an optimal design concept is developed. In the Design phase, elaboration of the design down to the smallest detail, production, and implementation planning is performed. In the Verify phase, complete implementation and monitoring of the KPI's is targeted (Lunau et al., 2009).

\section{$2.1 Q F D$}

The QFD is a quality improvement method used in the design of a new product and/or in the development of a better current product, which properly reflects its customer expectations and requirements (Delice et al., 2008). After deciding to use QFD to achieve product development, the next step should be to obtain necessary managerial commitment and support for the project. Then, decisions have to be made regarding the project's objectives. The next step is to define which concept or existing product (or product category) is going to be the object of the QFD project and which customers are targeted. Finally, a cross-functional team containing members from all tasks involved is assembled. Facilities, materials, and time necessary to carry out the project are made available by the management so that the team can begin (Costa et al., 2001). QFD, in principle, uses four matrices that integrate all the tasks involved (Partovi and Corredoira, 2002). 
Using the QFD method, the researcher associated 25 customer expectations with 25 quality characteristics in the matrix structure and calculated the weighted value of each characteristic according to the degree of difficulty, which then determined the priorities related to quality characteristics and customer expectations. These 25 characteristics were obtained both by negotiating with the customer and from previous bumper projects. Because the first three characteristics having the highest weighted value were applications of primer, paint, and varnish, the top priority in the improvement process was determined to be the paint, although all processes were still improved. In addition, a comparison was made with a rival company using the QFD structure.

During this phase, the QFD was created in seven steps described below with an example given for each part of the application as follows:

\section{Step 1: Customer expectations}

Collecting and analysing data about market expectations are two of the most challenging tasks for companies. In this study, customer expectations were determined by bringing together the lessons learned after the production and quality problems acquired in the previous bumper projects and the information during the project meetings with the customer. The production department contributed to the process by bringing together the technical knowledge and experience gained in previous projects, and the quality department contributed by combining the technical expertise and experience in the solution process of the experienced or predicted quality problems.

A customer expectations list was prepared by experts in the procurement, production, and quality; it consisted of a list of customer needs and the product characteristics that were expected. Considering customer expectations and levels of significance, the scores were ranked on a scale of 1-5. Accordingly, a research was conducted, and the importance levels (in parenthesis) determined from the evaluations were Moisture resistance (4), Resistance to chemicals (5), Resistance to deformation (3), and Adhesion (5).

\section{Step 2: Technical requirements}

In this phase, customer expectations are transformed into technical definitions that can be used during the engineering phase. The 'whats' are determined procurement, production, and quality groups, and the 'hows' are defined by the project team. In the matrix structure of the house of quality, the rows comprise customer expectations and their relative significance levels; the columns comprise engineering characteristics through which those expectations are realised (see Table 1).

Step 3: Customer expectations-technical identification relationship matrix

During this phase, the relationship between customer expectations and technical characteristics are usually expressed using a symbol. Some other authors can use different methods, such as a numeric scale. Lai et al. (2007) used a numeric scale in their QFD study paper. Related symbols are shown in Table 2. Table 3 was created using these symbols. 
Table 1 House of quality matrix

\begin{tabular}{|c|c|c|c|c|c|c|}
\hline $\begin{array}{l}\text { Demanded Quality } \\
\text { (a.k.a. Customer } \\
\text { Requirements or Whats) }\end{array}$ & $\begin{array}{r}\text { Quality Characteristics } \\
\text { (a.k.a. Functional } \\
\text { Requirements } \\
\text { or Hows) }\end{array}$ & 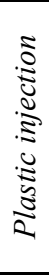 & $\frac{\infty}{i}$ & 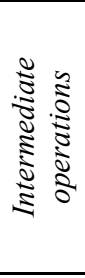 & 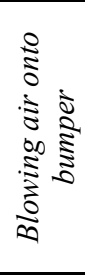 & 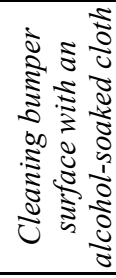 \\
\hline \multicolumn{7}{|l|}{ Appearance } \\
\hline \multicolumn{7}{|l|}{ Thickness } \\
\hline \multicolumn{7}{|l|}{ Pencil Hardness } \\
\hline \multicolumn{7}{|l|}{ Adhesion } \\
\hline Brightness & & & & & & \\
\hline
\end{tabular}

Table 2 Symbols and their meanings

\begin{tabular}{llc}
\hline Symbol & Relationship & Weighted value \\
\hline$\Theta$ & Strong & 9 \\
$\mathrm{O}$ & Medium & 3 \\
$\Delta$ & Weak & 1 \\
- & No relationship & 0 \\
\hline
\end{tabular}

Table 3 Impact of the hows on whats

\begin{tabular}{|c|c|c|c|c|c|}
\hline $\begin{array}{l}\text { Direction of Improvement: Minimise }(\mathbf{\nabla}), \\
\text { Maximise }(\mathbf{\Delta}) \text {, or Target }(X)\end{array}$ & $X$ & $X$ & $\boldsymbol{\Delta}$ & $\boldsymbol{\Delta}$ & $\Delta$ \\
\hline 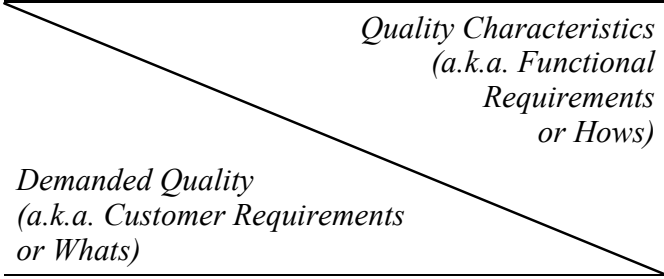 & 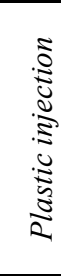 & 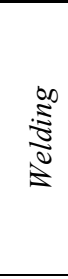 & 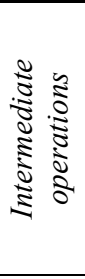 & 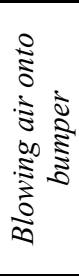 & 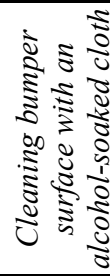 \\
\hline Appearance & $\mathrm{O}$ & $\Theta$ & $\Theta$ & $\mathrm{O}$ & $\Theta$ \\
\hline \multicolumn{6}{|l|}{ Thickness } \\
\hline \multicolumn{6}{|l|}{ Pencil Hardness } \\
\hline Adhesion & & & & $\mathrm{O}$ & $\mathrm{O}$ \\
\hline Brightness & & & & & \\
\hline
\end{tabular}

Additionally, each technical requirement has a direction of improvement that maximises customer satisfaction. The following symbols are used in expressing this direction:

$\boldsymbol{\nabla}$ : Target value is the best goal. When there is a difficulty achieving the goal, it should be below this target.

$\boldsymbol{\Delta}$ : Target value is the best goal. When there is a difficulty achieving the goal, it should be above this target. 
$X$ : Realisation of the target is best for customer satisfaction.

Step 4: Technical indicator correlation matrix

While forming the 'roof' of the QFD, the triangular correlation matrix (see Table 4) is used to show the correlation among the technical characteristics. Significance levels of internal relationships among the characteristics are indicated by the following symbols: ' ++ ' is for 'Strongly positive, ' + ' is for 'Positive', and '-' is for 'Negative.'

For example, a positive relationship was determined between plastic injection and welding, while a strongly positive relationship was found between blowing air onto the bumper and cleaning the bumper surface with an alcohol-soaked cloth.

Table 4 The roof of the house of quality (partial)

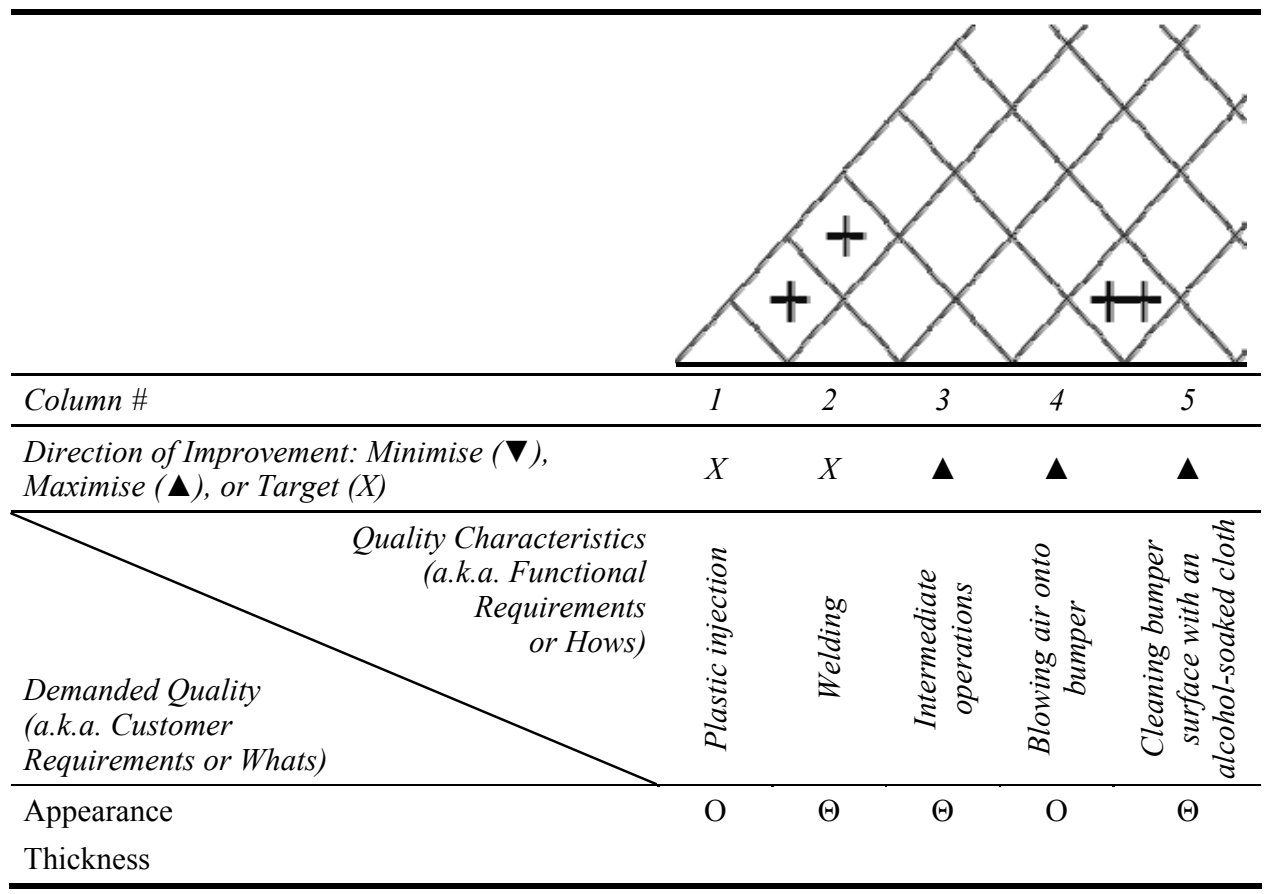

Step 5: Determination of the company's goals and targets

This step investigates the answer to the question 'how much' with regard to each engineering characteristic. The company's target to meet customer expectations should be determined. During this phase, it is necessary to determine the benchmark needed to meet customer expectations when the new product is released into the market, as shown in Table 5 .

\section{Step 6: Competition matrices}

Competition matrices compare a company's current product with the rivals' products. In this regard, the rival products on the market are evaluated in terms of engineering and customer perspectives. In the evaluation, products are scored from 1 to 5 , with 1 being the worst and 5 being the best. 
Table 6 shows the competition matrix, which compares the company that is applying QFD with a rival company.

Table 5 Determination of the company's goals and targets

\begin{tabular}{|c|c|c|c|c|c|c|c|c|c|}
\hline $\begin{array}{r}\text { Quality } \\
\text { Characteristics } \\
\text { (a.k.a. Functional } \\
\text { Requirements } \\
\text { or Hows) }\end{array}$ & 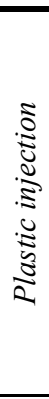 & $\frac{\mathfrak{0}}{\frac{0}{0}}$ & 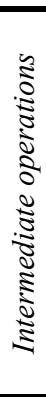 & 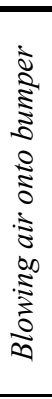 & 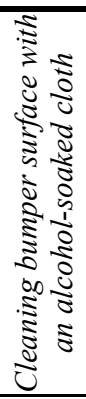 & 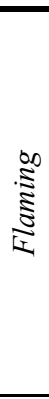 & 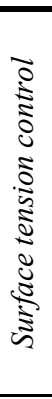 & 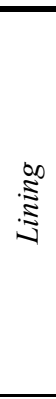 & 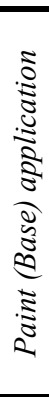 \\
\hline Target or Limit Value & 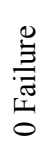 & 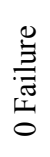 & 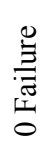 & 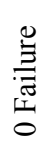 & $\begin{array}{l}\stackrel{0}{\Xi} \\
: \vec{\Xi} \\
\text { 岌 } \\
0\end{array}$ & 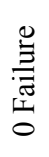 & 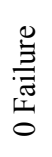 & 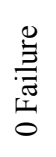 & 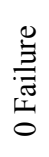 \\
\hline $\begin{array}{l}\text { Difficulty }(0=\text { Easy, } 10=\text { Very } \\
\text { Hard })\end{array}$ & 8 & 8 & 6 & 6 & 6 & 7 & 6 & 8 & 8 \\
\hline
\end{tabular}

Table 6 Competition matrix (see online version for colours)

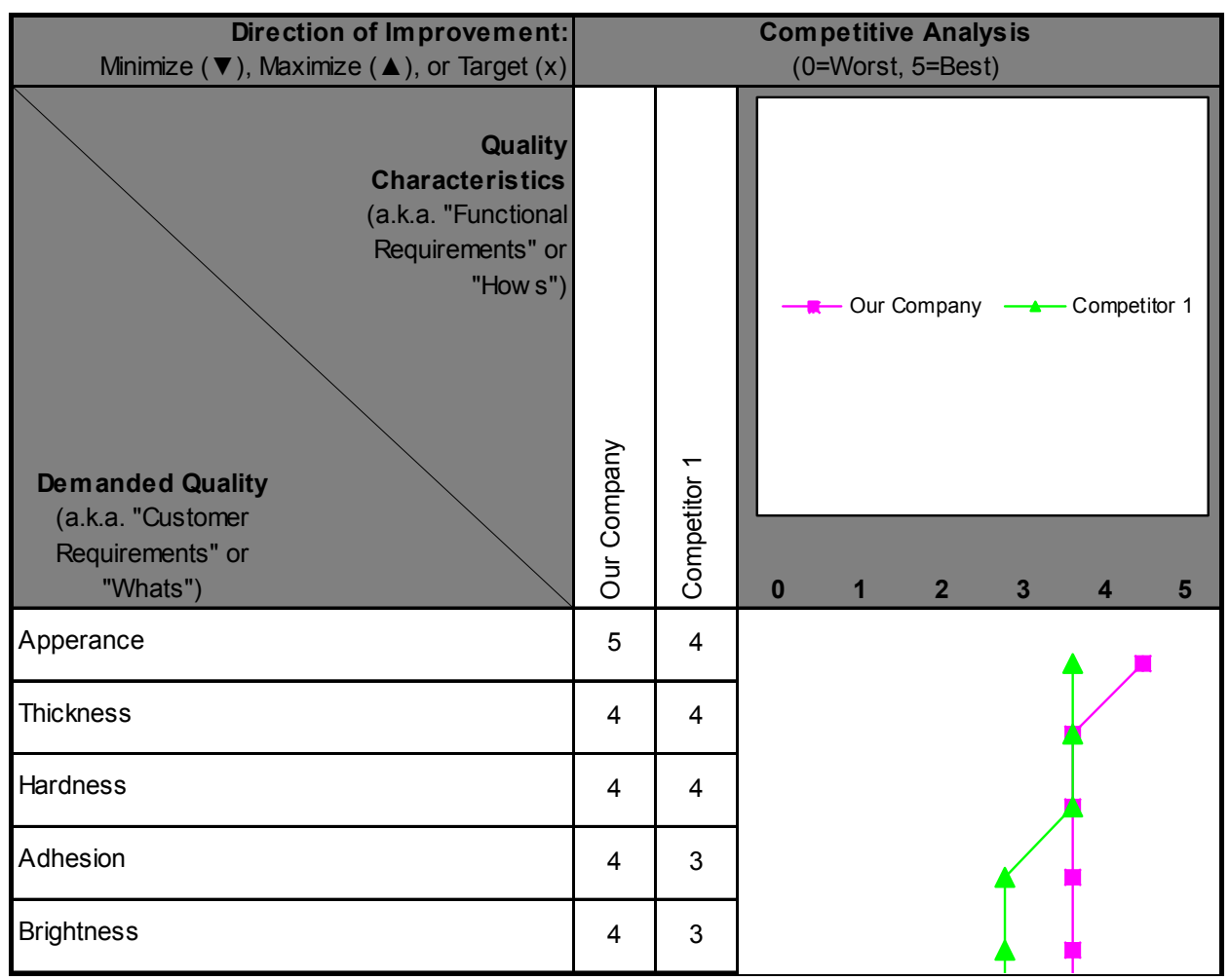


Step 7: Determination of priority customer demands and technical characteristics

During this step, each engineering characteristic and the relative and absolute significance levels in meeting customer expectations are calculated using a specific formula, as shown in Table 7.

Because the first three characteristics with the highest weighted value were applications of primer, paint, and varnish, the priority characteristics for improvement was determined to be paint, although all processes were taken into consideration and improved.

\section{$2.2 F M E A$}

FMEA is an improvement and development tool that aims to prevent an error in design, process, and delivery processes at the earliest possible stage before reaching the customer. The FMEA study should include the knowledge from past warranty problems, if any, customer and performance requirements, drawings and specifications, and process mappings. For each functional requirement and related process, the cross-functional team needs to ask the question, "What can go wrong?". Therefore, it is necessary to determine the possible design and process failure modes and sources of potential variation in all related processes. Considerations include deviations in customer usage, potential causes of wear over useful product life, and potential process issues (i.e., missed tags or steps, shipping problems, service misdiagnosis). The team should modify product design and processes to prevent "problematic things" from happening and involve the development of strategies to deal with different situations, the redesign of processes to reduce variation, and error-proofing of designs and processes. The process of anticipating failure modes and sources of variation is iterative, and it continues as the team attempts to further improve the design and its processes (Yang and El-Haik, 2003).

Table 7 Comparative characteristic weights

\begin{tabular}{|c|c|c|c|c|c|c|c|c|c|}
\hline $\begin{array}{l}\text { Quality } \\
\text { Characteristics } \\
\text { (Functional } \\
\text { Requirements or } \\
\text { Hows) }\end{array}$ & 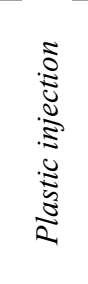 & $\frac{\infty}{\stackrel{\Xi}{0}}$ & 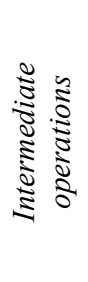 & 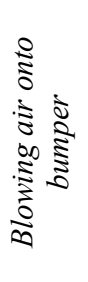 & 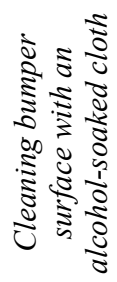 & 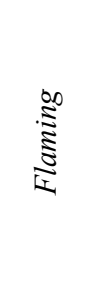 & 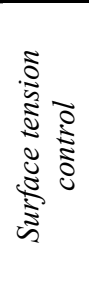 & 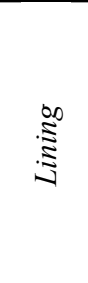 & 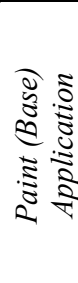 \\
\hline $\begin{array}{l}\text { Maximum relation } \\
\text { value in column }\end{array}$ & 9 & 9 & 9 & 3 & 9 & 9 & 9 & 9 & 9 \\
\hline Weight/significance & 252.0 & 96.0 & 62.0 & 42.0 & 72.0 & 285.0 & 140.0 & 298.0 & 328.0 \\
\hline Related weight & 8.1 & 3.1 & 2.0 & 1.3 & 2.3 & 9.1 & 4.5 & 9.5 & 10.5 \\
\hline
\end{tabular}

In this study, an FMEA study was conducted for the project, including their related departments. An evaluation of the pre- and post-conditions was made in accordance with customer expectations and their significance levels. Processing improvements were suggested, especially for critical processes having higher scores. The FMEA study was applied to all related processes, beginning with the process having the highest weighted value in the house of quality application. Fifty-five failure modes were investigated in 
this application, and 35 failure modes were improved. In this paper, only the most influential FMEA calculations are given for completeness. In the application of the FMEA method, the cause of each potential failure is determined, its impact on the customer is evaluated, the controls performed are examined, regulatory activities are recommended, and their recommended implementation is followed.

Three components used in determining failure priority are as follows:

- $\quad$ probability $(\mathrm{P})$

- $\quad$ intensity (I)

- $\quad$ detectability (D).

The probability $(\mathrm{P})$ is the frequency with which failure occurs, the intensity (I) is the impact of that failure, and detectability (D) indicates the detection level of the failure before the product has been delivered to the customer. There are numerous methods by which the values of these components are determined, and the typical approach is to use numerical ranges. The steps in the technique related to this study are as follows:

- determining the probability values

- determining the intensity value

- determining the detectability value

- calculating the $\mathrm{RPN}(\mathrm{R} \times \mathrm{P} \times \mathrm{N})$

- $\quad$ creating the FMEA form.

The value of the probability that a failure could occur indicates, as a result of the reasons identified, that the failure could occur without being detected when the product is with the customer or user. Intensity is the determination of the effects of the potential failure for the customer. Detectability is the degree of preventing the failure from reaching the customer after identifying the potential failure using current controls.

The FMEA study was conducted for injection, paint, and assembly processes. Table 8 provides a list of the issues identified for the dirt/foreign matter problem in the painting process. The effect of this failure causes appearance disorders and leads to customer dissatisfaction. Its intensity level is chosen as 7 according to prior knowledge. The reasons for this failure can be as follows:

- inappropriate cabin filters

- dust and pile coming from the paint

- $\quad$ burst paint filters

- inappropriate gloves, clothes, and tack rag in manual application

- dirty part surface

- inappropriate environmental cleaning

The probability level of this failure is 5 . The current process controls are as follows:

- $\quad$ operator training

- $\quad$ operator working directives 
- control of the paint

- $\quad$ putting each paint drum into production after filtering

- control of filters

Table 8 Example of FMEA for the painting process

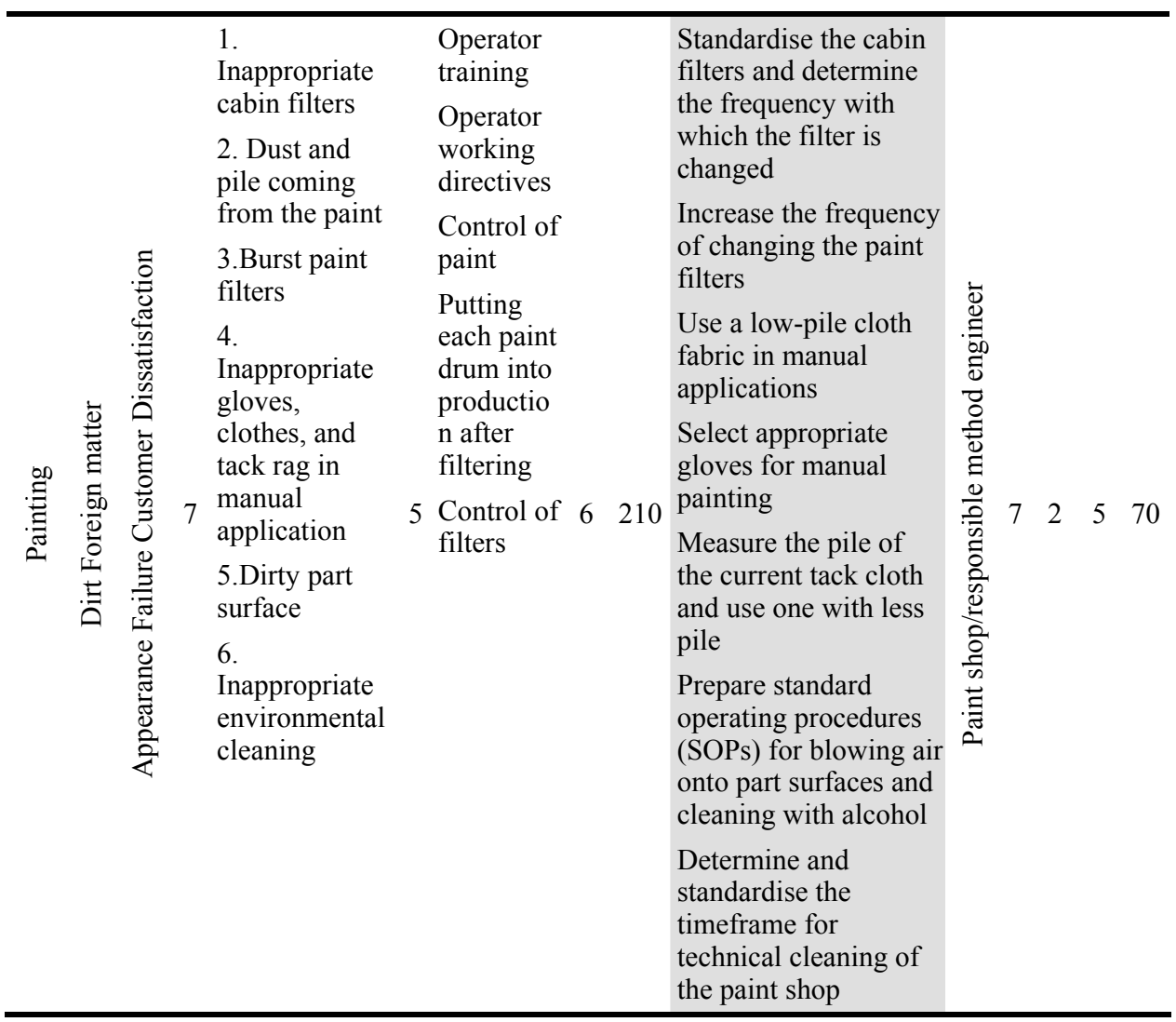

The detectability level of the failure is 6 . Therefore, for preconditions, RPN is calculated as $7 \times 5 \times 6=210$. In order to eliminate this failure, the recommended activities are decided as follows:

- $\quad$ standardise the cabin filters and determine the filter change period,

- change the paint filters more frequently,

- use a cloth fabric in the manual application that does not cause pile,

- use appropriate gloves for manual painting,

- measure the pile of the current tack cloth and use a tack cloth with less pile,

- $\quad$ prepare standard operating procedure s(SOPs) for blowing air onto part surfaces and cleaning with alcohol, and

- determine and standardise the timeframe for technical cleaning by the paint shop. 
After the responsible personnel of the department has applied the proposed activities, the intensity level is now chosen as 7, the probability level is now 2, and the detectability level is now 5 . The new RPN is calculated as $7 \times 2 \times 5=70$.

Table 9 shows the FMEA study on the problem of installing fog lamps in the wrong position in the assembly process. The effects of this failure are the wrong assembly part, labour loss, and waste. The intensity level is 6 , and the reason for the failure is operator carelessness. The probability level is 7 . The control of the current process is visual operating procedures and visual control. The detectability level is 6 . For the preconditions, RPN is $6 \times 7 \times 6=252$. The recommended activities are bridging the position suitable for the installation of fog lamps on the assembly table using poka-yoke techniques. After the responsible personnel of the department and the assembly table's manufacturer have applied the proposed activities, the intensity level is now 6 , the probability level is 2 , and the detectability level is 1 . The new RPN is calculated as $6 \times 2 \times 1=12$.

Table 9 Example of the FMEA for the assembly process

\begin{tabular}{|c|c|c|c|c|c|c|c|}
\hline $\begin{array}{l}\text { Manual } \\
\text { assembly } \\
\text { preparation } \\
\text { (front } \\
\text { bumper) }\end{array}$ & $\begin{array}{l}\text { Assembling } \\
\text { fog lamps } \\
\text { in the } \\
\text { wrong } \\
\text { position }\end{array}$ & $\begin{array}{l}\text { Wrong } \\
\text { part } \\
\text { assembly, } \\
\text { labour } \\
\text { loss and } \\
\text { waste }\end{array}$ & $\begin{array}{c}6 \text { Operator } \\
\text { carelessness }\end{array}$ & $\begin{array}{l}7 \text { Visual } \\
\text { operating } \\
\text { procedure, } \\
\text { visual } \\
\text { control }\end{array}$ & $\begin{array}{l}6252 \text { Bridging the } \\
\text { position } \\
\text { suitable for } \\
\text { the } \\
\text { installation of } \\
\text { fog lamps on } \\
\text { the assembly } \\
\text { table using } \\
\text { the poka- } \\
\text { yoke } \\
\text { technique }\end{array}$ & $\begin{array}{l}\text { Assembly } \\
\text { responsible/ } \\
\text { assembly } \\
\text { table's } \\
\text { manufacturer }\end{array}$ & $\begin{array}{llll}6 & 2 & 1 & 12\end{array}$ \\
\hline
\end{tabular}

Table 10 shows the FMEA study conducted for the impact of mark problems in the injection process. The effects of failure are visually negative evaluations by the customer and an empty line. The intensity level is 7 , and the reason for failure is based on injection and packaging after injection. The probability level is 3 . The current control of the process is visual control and $100 \%$ control. The detectability level is 6 . For the preconditions, RPN is $7 \times 3 \times 6=126$. The recommended activities are to use an ergonomic transport trolley to provide internal transportation between the injection and paint shop sections. After the responsible personnel of the department has applied the proposed activities, the intensity level is now 7 , the probability level is 2 , and the detectability level is 5 . The new RPN is calculated as $7 \times 2 \times 5=70$.

\subsection{Experimental design}

The experimental design was performed by Besterfield et al. through identifying the variability on the response variable, performing the desired change on the input variable of the process (Akman and Özkan, 2011). The experimental design is essential in optimising the process and reducing process variability by defining process variables. Figure 2 shows the general model of a system or process. Here, process variables are called as $X_{1}, X_{2}, \ldots, X_{p}$ (also known as controllable variables), and $Z_{1}, Z_{2}, \ldots, Z_{q}$ are uncontrollable variables (Lunani et al., 1997). 
Table 10 Example of the FMEA for the injection process

\begin{tabular}{|c|c|c|c|c|c|c|c|c|c|c|c|}
\hline Burr & $\begin{array}{l}\text { Visually } \\
\text { negative } \\
\text { evaluation } \\
\text { by the } \\
\text { customer } \\
\text { and empty } \\
\text { line }\end{array}$ & $\begin{array}{l}6 \text { Injection- } \\
\text { based }\end{array}$ & 3 & $\begin{array}{l}\text { Visual } \\
\text { control } \\
+100 \% \\
\text { Control }\end{array}$ & 6 & 108 & & & & & \\
\hline $\begin{array}{l}\text { Mould } \\
\text { mark, } \\
\text { feathering } \\
\text { mark }\end{array}$ & $\begin{array}{l}\text { Visually } \\
\text { negative } \\
\text { evaluation } \\
\text { by the } \\
\text { customer } \\
\text { and empty } \\
\text { line }\end{array}$ & $\begin{array}{l}7 \text { Injection- } \\
\text { based }\end{array}$ & 3 & $\begin{array}{l}\text { Visual } \\
\text { control } \\
+100 \% \\
\text { Control }\end{array}$ & 6 & 126 & & & & & \\
\hline $\begin{array}{l}\text { Sandpaper } \\
\text { mark }\end{array}$ & $\begin{array}{l}\text { Visually } \\
\text { negative } \\
\text { evaluation } \\
\text { by the } \\
\text { customer } \\
\text { and empty } \\
\text { line }\end{array}$ & $\begin{array}{l}7 \text { Injection- } \\
\text { based }\end{array}$ & 3 & $\begin{array}{l}\text { Visual } \\
\text { control } \\
+100 \% \\
\text { Control }\end{array}$ & 6 & 126 & & & & & \\
\hline $\begin{array}{l}\text { Impact } \\
\text { mark }\end{array}$ & $\begin{array}{l}\text { Visually } \\
\text { negative } \\
\text { evaluation } \\
\text { by the } \\
\text { customer } \\
\text { and empty } \\
\text { line }\end{array}$ & $\begin{array}{l}7 \text { Injection- } \\
\text { based and } \\
\text { packaging- } \\
\text { based after } \\
\text { injection }\end{array}$ & 3 & $\begin{array}{l}\text { Visual } \\
\text { control } \\
+100 \% \\
\text { Control }\end{array}$ & 6 & 126 & $\begin{array}{l}\text { An ergonomic } \\
\text { transport } \\
\text { trolley that will } \\
\text { provide the } \\
\text { internal } \\
\text { transportation } \\
\text { between } \\
\text { injection and } \\
\text { paint shop } \\
\text { sections }\end{array}$ & $\begin{array}{l}\text { Injection } \\
\text { responsible/ } \\
\text { paint shop } \\
\text { responsible/ } \\
\text { method } \\
\text { engineer }\end{array}$ & & 25 & $5 \quad 70$ \\
\hline
\end{tabular}

Figure 2 General representation of a system or process

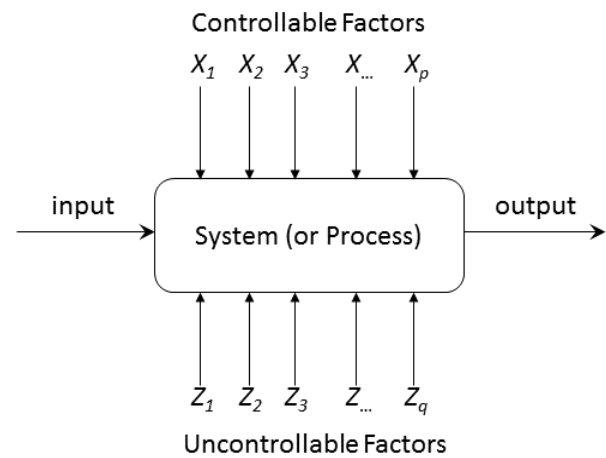

Experimental design methods are important for the improvement of the current process, for the development of a new process, and the improvement of performance. The goal is to develop a strong and determined process. In summary, it is aimed to develop a process in which the effects of variability source, uncontrollable variable $\left(Z_{1}, Z_{2}, \ldots, Z_{q}\right)$, are kept to a minimum (Montgomery, 2013). 
When more than one factor is found effective in an experimental structure, the factorial design method should be preferred. A factorial design is the type of study performed by testing all possible combinations of levels of each factor (Lazić, 2004). The analysis of variance in a factorial design explains the factors and their importance in the current process with numerical data (Yang and Tarng, 1998). Furthermore, regression analysis is used to determine the existence of a clear mathematical relationship between the cause (independent input variable) and the result (dependent output variable) (Hamzaçebi and Kutay, 2003). The effect of a factor on the experiment can be calculated utilising the aforementioned methods. In addition, the method supports the determination of the source of the difference without changing the order of operation (Breyfogle, 2003). A DOE project includes many steps such as project definition, selection of response variable (output), choice of factors, levels and ranges, select an experimental design, perform the experiment, analysis of DOE data, conclusions, and recommendations (Yang and El-Haik, 2003).

Factorial designs are widely used where there are many factors, and there are compound effects of factors on the output variable. The $2^{\mathrm{k}}$ experimental design, where each factor has two levels, is the most common. It is used especially in the early stages of experimental studies where the factor level is high because the full factorial design for $\mathrm{k}$ factors provides the opportunity to conduct a minimum number of experiments. Factor levels are generally defined as low and high; - is used for low levels and + for high levels (Montgomery, 2013).

To find the principal or compound effect of a factor, coefficients of the corresponding trial combinations are taken into account by the - and + signs below that factor. The effect of the factor of interest is calculated by taking into account the determined coefficients.

In this study, $2^{\mathrm{k}}$ experimental design method was used. The reasons for choosing a $2^{\mathrm{k}}$ experimental design method instead of $3^{\mathrm{k}}$ experimental design method are: analysis is generally better, no midpoint is used as linear dependence is assumed, and the produced part has two levels, such as proper or improper outputs.

In this study, the production process consists of three primary process stages as explained before; injection, painting, and assembly. For each process, the most common types of errors encountered in the customer and the factors thought to affect the errors were analysed with numerical data using the Minitab 18 software. The error types examined are given as follows:

- In the injection process: Missing injection and scratch.

- In the painting process: Paint leakage, crater, and dust.

- In the assembly process: Priority error types in all processes such as version error, incomplete assembly, and visual problematic errors such as friction, scratches, and impacts.

In all of the errors above, dust was identified to be one of the leading problems. Dust and dirt on the surface are very serious problems; the presence of foreign particles caused by the application of the surface, paint, paint preparation processes, application equipment, or cabinet produces improper parts. Figure 3 depicts microscopic examples of dust/dirt on the surface.

Common reasons for dust/dirt on the surface are: 
- dust from the environment or uncleaned vehicle during application

- $\quad$ sanding dust remains on the surface

- fibres rupture from torn areas of masking papers

- dust from application clothing

- dirty cabin walls

- clogged cabin filters

- dirt on the outside of the air tube

- cabin pressure is lower than external pressure.

For the removal of dust/dirt on the surface, the following can be done:

- during the spraying process, dust particles can be removed with a needle

- dried paint film dust can be removed by a paste-polish process

- $\quad$ if the powder is very dense, paste polish is applied after sanding or repainting is done.

As the dust/dirt problem was identified as one of the leading factors, an in-depth analysis was performed. In order to identify important factors affecting the dust problem, a cause and effect (Ishikawa) diagram of the dust failure type was prepared (see Figure 4). In this diagram, the effects that are shown with the green OK mark indicate the factors that do not affect the errors. On the other hand, the effects shown with a red X mark indicate the factors that affect the errors.

Figure 3 Sample of dust/dirt on the surface: (a) prior to application of the paint, samples of the microscopic image of the contaminations on the screen, dust; (b) prior to application of the paint, samples of microscope images of the supernatant contaminants, fibres and (c) sieve image of a problematic paint drained before application, particle (see online version for colours)

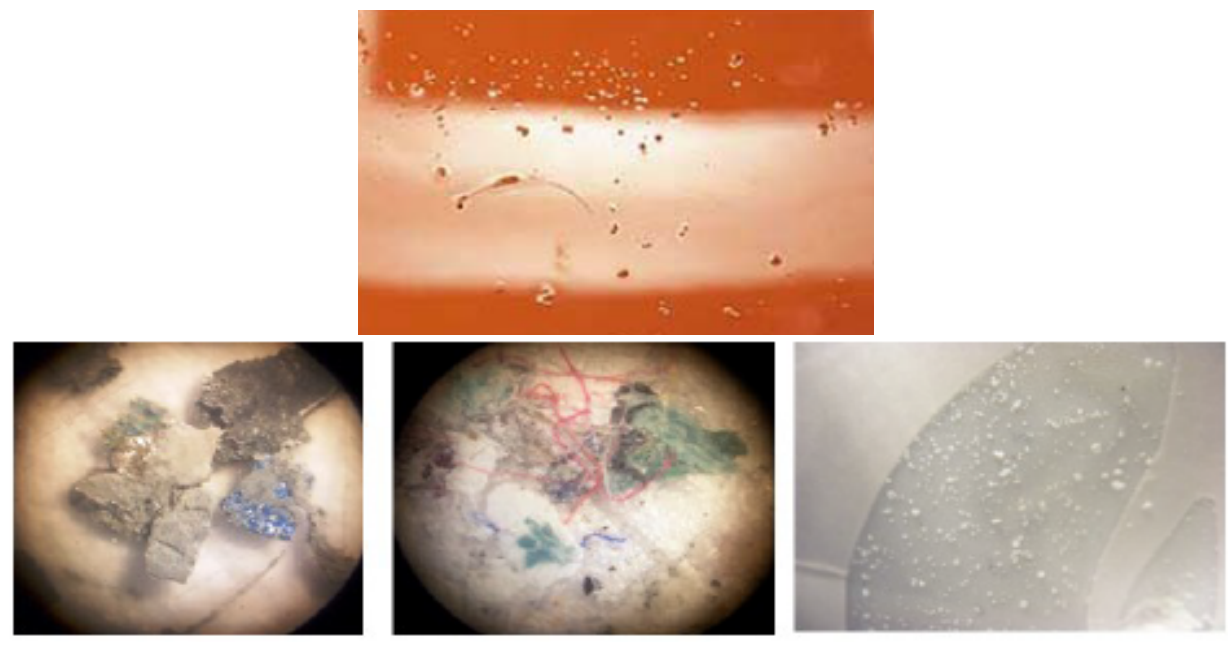

(a)

(b)

(c) 
As a result of this cause and effect analysis, the identified (and decided) factors related to the dust failure type were application clothing, cabin filter, and sanding powder on the surface. In this study, as these three factors are chosen, $2^{3}$ factorial designs were performed with four replications for a total of 32 samples, and the results were analysed in Minitab 18 software. Minitab analysis results are shown in Figures 5-8 and Table 11. Figure 5 shows the normal plot of the standardised effects and indicates that all three factors are effective. Additionally, two interactions also seem to be effective: cabin filter and sanding powder $(\mathrm{BC})$, application clothing, cabin filter, and sanding powder (ABC). Figure 6, on the other hand, provides the validity of the experiment, providing residuals. Figures 7 and 8 provide the effects and show the interactions.

Figure 4 Cause and effect diagram for dust error type (see online version for colours)

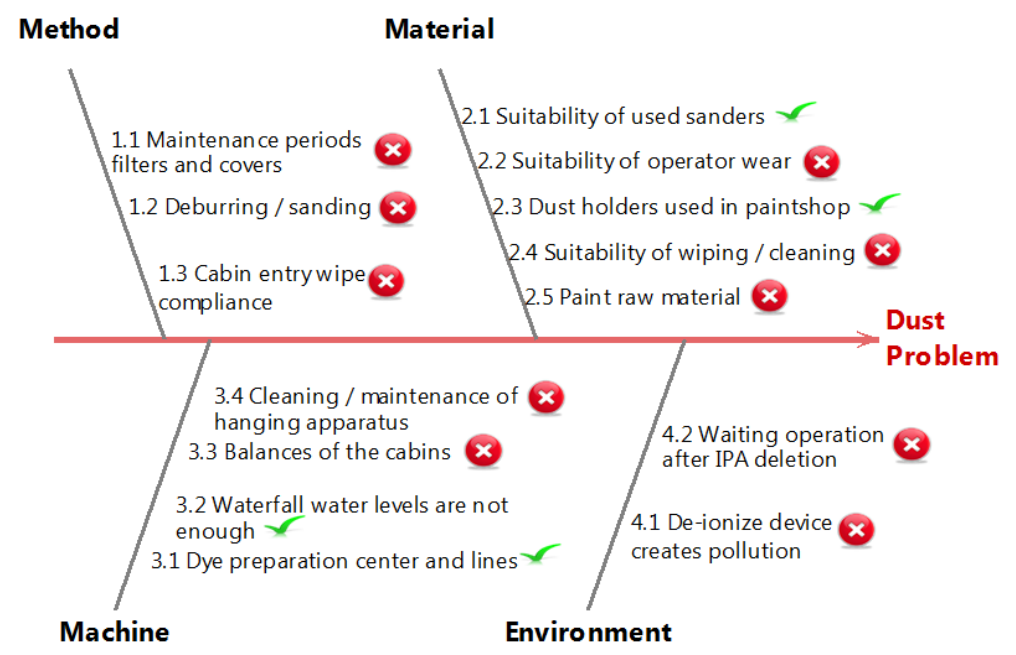

Figure 5 Normal plot of the standardised effects for dust error type (before) (see online version for colours)

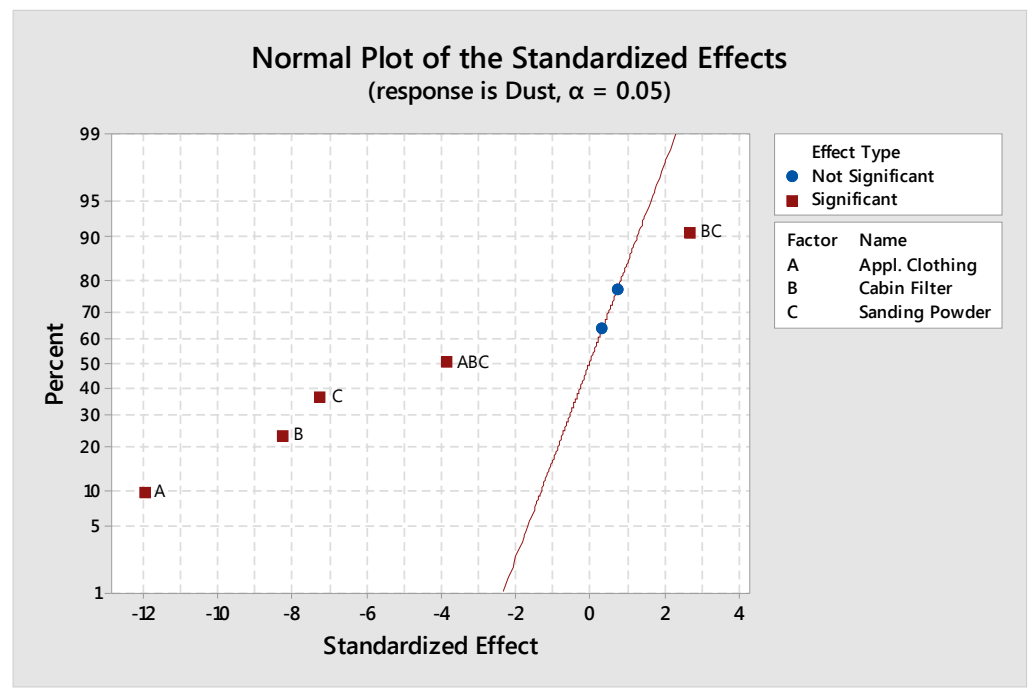


Table 11 shows the regression analysis of the experimental design. The error sum of squares is much less than the sum of squares of the main effects (137 to 1640.88), and the degrees of freedom of the error is much larger than the model (24 to 3), which indicated that the experimental design has identified the important factors and omitted almost nothing. Also, according to Minitab analysis results, the $R^{2}$ value was $92.29 \%$ (and $R^{2}$ (adj) $90.05 \%$ ). Usually, a benchmark value of $85 \%$ is used for comparison, and since $R^{2}$ is greater than $85 \%$ in this case, it is concluded that the linear approximation explains the model well. Therefore the regression equation obtained as a result of the analysis can also be used in the experimental range for further analysis, if needed.

Figure 6 Residual plots for dust error type (before) (see online version for colours)

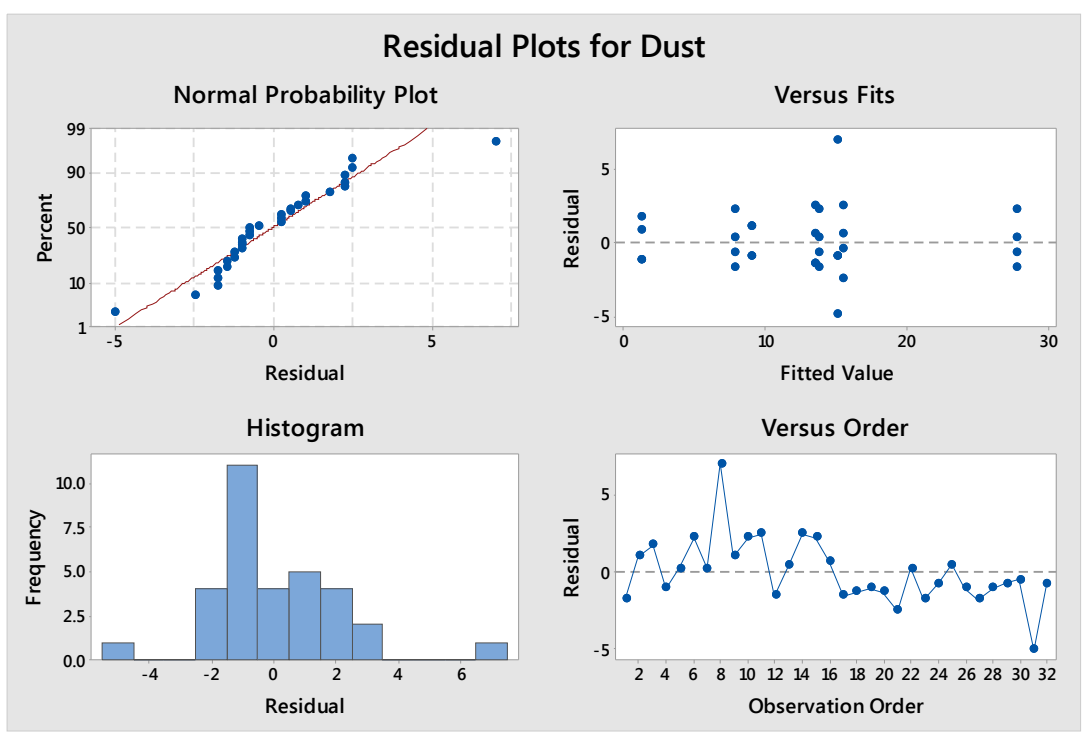

Figure 7 Main effects plot for dust error type (Before) (see online version for colours)

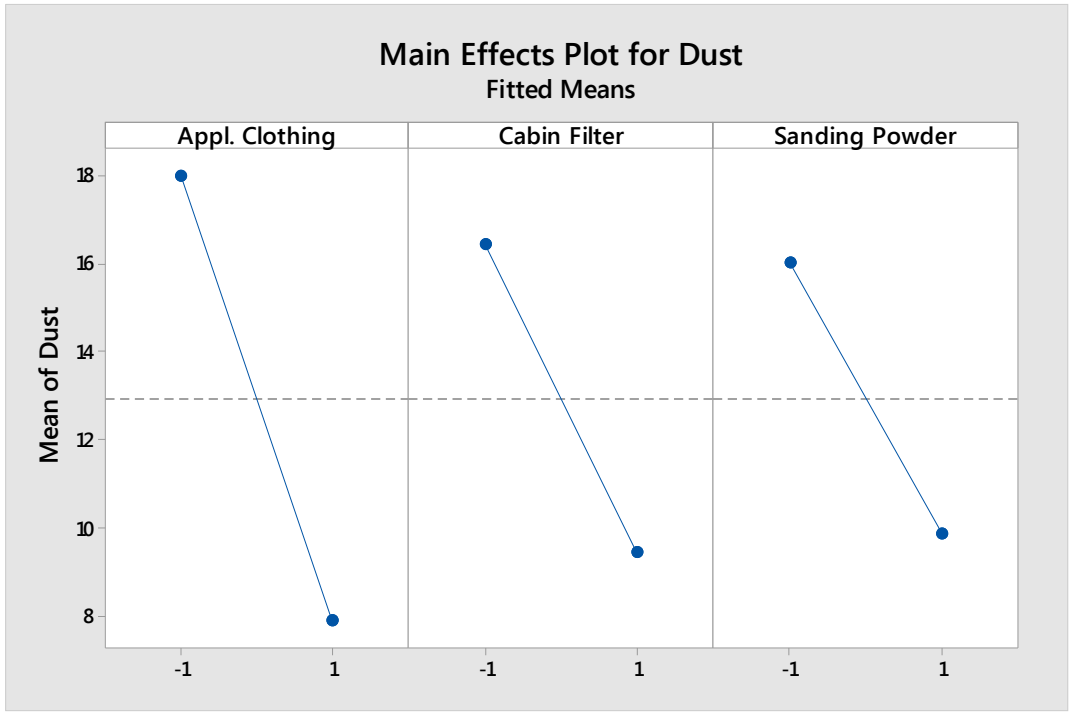


Table 11 Minitab analyses ANOVA values for dust error type (before)

\begin{tabular}{lccccc}
\hline Source & DF & Adj SS & Adj MS & F-Value & P-Value \\
\hline Model & 7 & 1640.88 & 234.411 & 41.06 & 0.000 \\
Linear & 3 & 1512.25 & 504.083 & 88.31 & 0.000 \\
Application Clothes & 1 & 820.12 & 820.125 & 143.67 & 0.000 \\
Cabin Filter & 1 & 392.00 & 392.000 & 68.67 & 0.000 \\
Sanding Dust on the Surface & 1 & 300.12 & 300.125 & 58.52 & 0.000 \\
2-Way Interactions & 3 & 44.13 & 14.708 & 2.58 & 0.077 \\
Application Clothes*Cabin Filter & 1 & 0.50 & 0.500 & 0.09 & 0.770 \\
$\begin{array}{l}\text { Application Clothes*Sanding Dust on } \\
\text { the Surface }\end{array}$ & 1 & 3.13 & 3.125 & 0.55 & 0.467 \\
Cabin Filter*Sanding Dust on the & 1 & 40.50 & 40.500 & 7.09 & 0.014 \\
Surface & & & & & \\
3-Way Interactions & 1 & 84.50 & 84.500 & 14.80 & 0.001 \\
$\begin{array}{l}\text { Application*Cabin Filter*Sanding Dust } \\
\text { on the Surface }\end{array}$ & 1 & 84.50 & 84.500 & 14.80 & 0.001 \\
Error & 24 & 137.00 & 5.708 & & \\
Total & 31 & 1777.88 & & & \\
\hline
\end{tabular}

Figure 8 Interaction plot for dust error type (before) (see online version for colours)

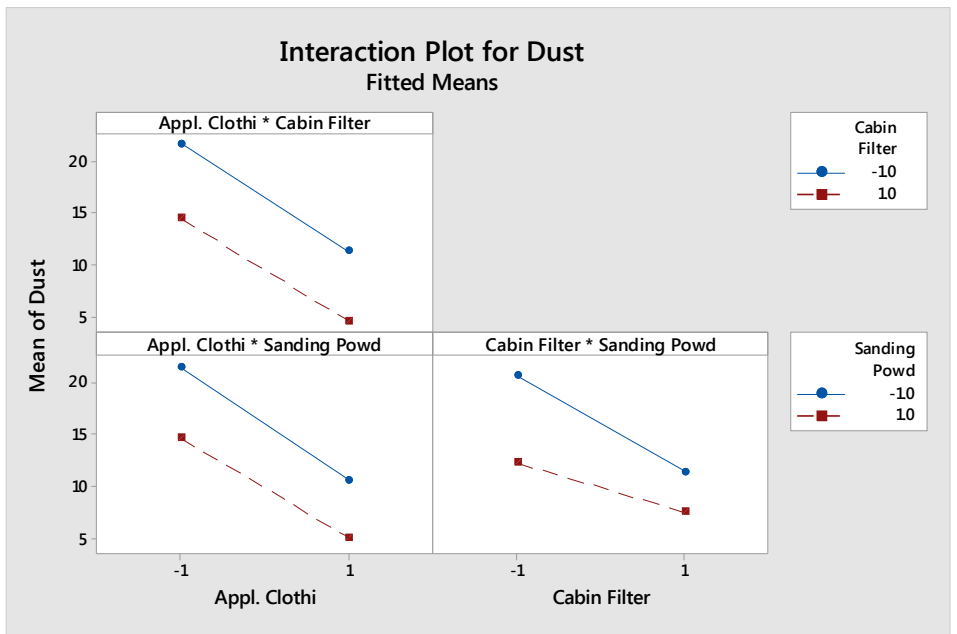

After the experimental design, there is much to be done in the design phase of the bumper for improvements. In the next section, further improvements are given with the experimental design results after these improvements.

\section{Further improvements in the design phase}

In this section, further improvements in the design phase and its results are provided. In the project design process, starting from parameter optimisation in the injection process, 
determination of internal transport standard and the making of carriage prototypes, optimisation of the number of parts to be loaded to the skids in the painting process, and robot programming by starting parameter optimisation studies are accomplished. Furthermore, the application of painted part stocking and installation of first in first out (FIFO) logic and new layout works of the line and all related poka-yoke works of the assembly counters were designed. Even the optimisation of the number of people to work and the optimisation of the shipment works were realised.

In the painting process, the dust problem is analysed, as seen in Figures 9-11. These pictures depict examples of the dust problem. First, dust particles detected on the part were examined with the help of a microscope, and the structure was analysed, and then the sources causing dust were determined. Figure 9 is an example of the dust that is the same colour as the paint. Figure 10 shows an example of dust that has a different colour from the paint. Figure 11 shows a dust cluster.

Figure 9 Example of dust that is the same colour as the paint (see online version for colours)

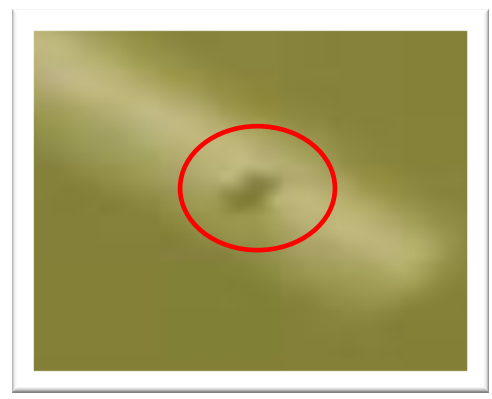

Figure 10 Example of dust that is a different colour from the paint (see online version for colours)

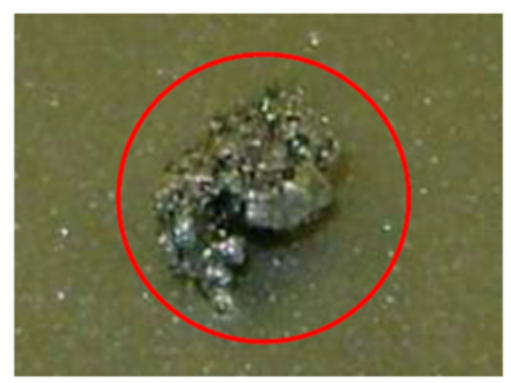

Figure 11 Example of dust cluster (see online version for colours)

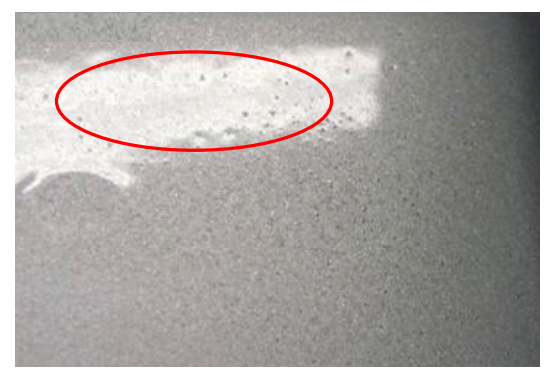


In accordance with the analysis made using a microscope, the most appropriate application clothes were determined by using pile measurement and started to be used. Then, the appropriate type for cabin filter was determined and began to be changed in the specified periods. After the sanding process before painting, the air gun used in the cleaning process in the loading area of the paint shop was changed, and operators now performed the cleaning process within the framework of the determined standard route.

The reflection of the improvement studies carried out for the three main process phases, injection, paint, and assembly in the production process was checked, and the factor effects were verified. For each step, the most common types of errors encountered in the customer and the factors that are thought to affect the errors were analysed with numerical data in Minitab 18 software to verify the situation after the improvement studies. For this purpose, the following failure modes are chosen for each process:

- In the injection process: Missing injection and scratch

- In the painting process: Paint leakage, crater, and dust

- In the assembly process: Version error, incomplete assembly, and friction scratchimpact

The identified factors related to the dust were stated before as; application clothing, cabin filter, and sanding powder on the surface. In this study (after improvements), more $2^{3}$ factorial designs were performed with 4 replications for 32 samples, and the results were analysed in Minitab 18 software. Minitab 18 analysis results for the case are shown in Figures 12-15 and Table 12. Figure 12 shows that all three factors are effective, together with application of clothing and cabin filter interaction (AB). Figure 13 shows the validity of the experimental design, providing residuals. Figures 14 and 15 show the effects of the main factors and interactions. As a result of the analysis, the interaction between application clothing, cabin filter, and sanding powder factors on the surface and application clothing and cabin filter were found to be effective.

Figure 12 Normal plot of the standardised effects for dust error type (after) (see online version for colours)

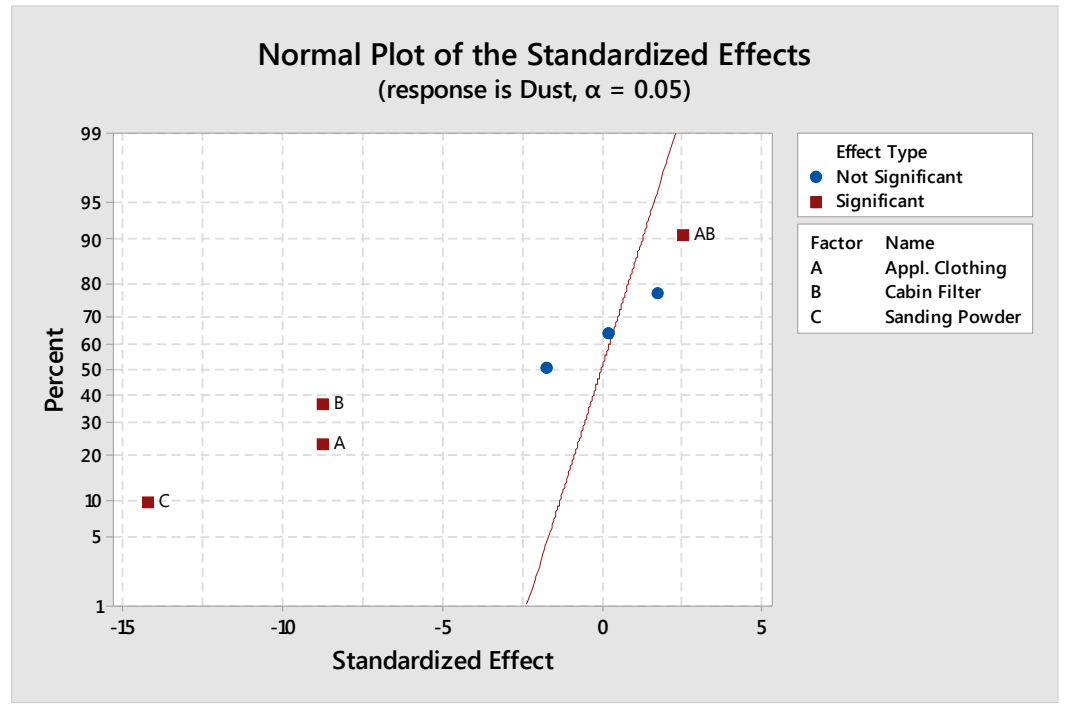


Table 12 shows the regression analysis of the experimental design. The same argument as in Table 11 holds, and the experimental design has identified the important factors and omitted almost nothing. As $R^{2}$ value was $93.89 \%$ (and $R^{2}$ (adj) $92.11 \%$ ) well above $85 \%$, once more, it is concluded that the linear approximation explains the model well. Therefore, the regression equation can also be used in the experimental range for further analysis, if needed.

Figure 13 Residual plots for dust error type (after) (see online version for colours)

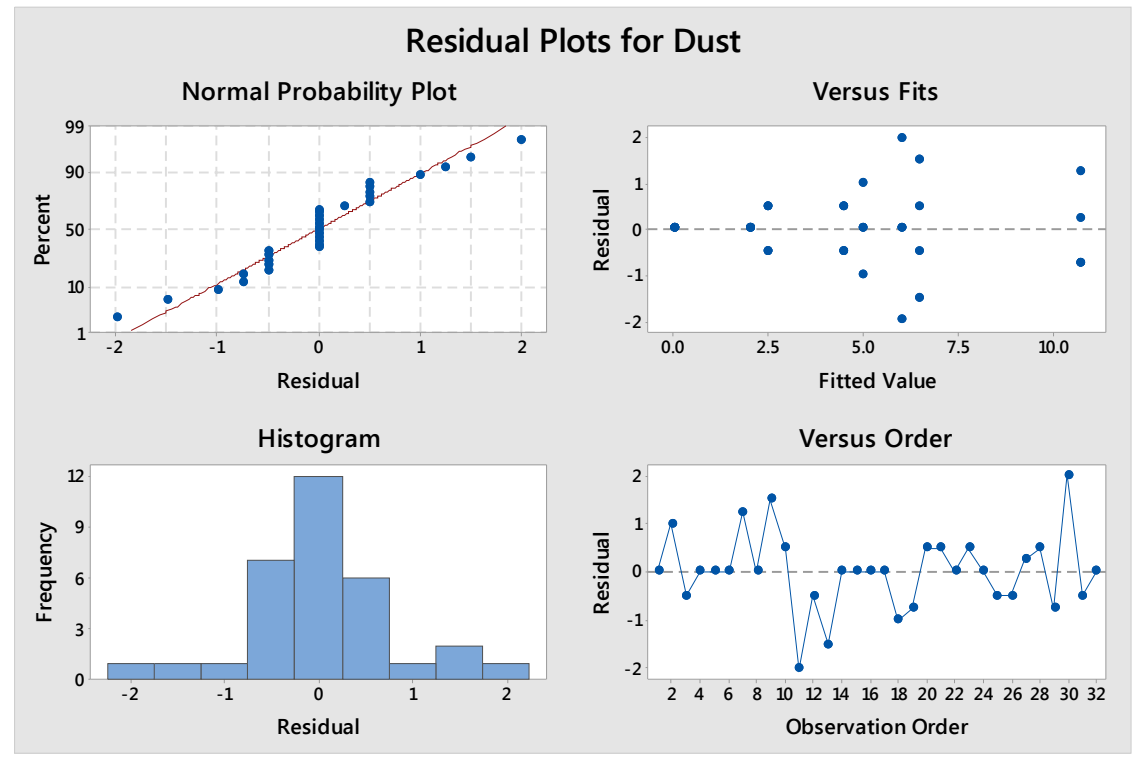

Figure 14 Main effects plot for dust error type (after) (see online version for colours)

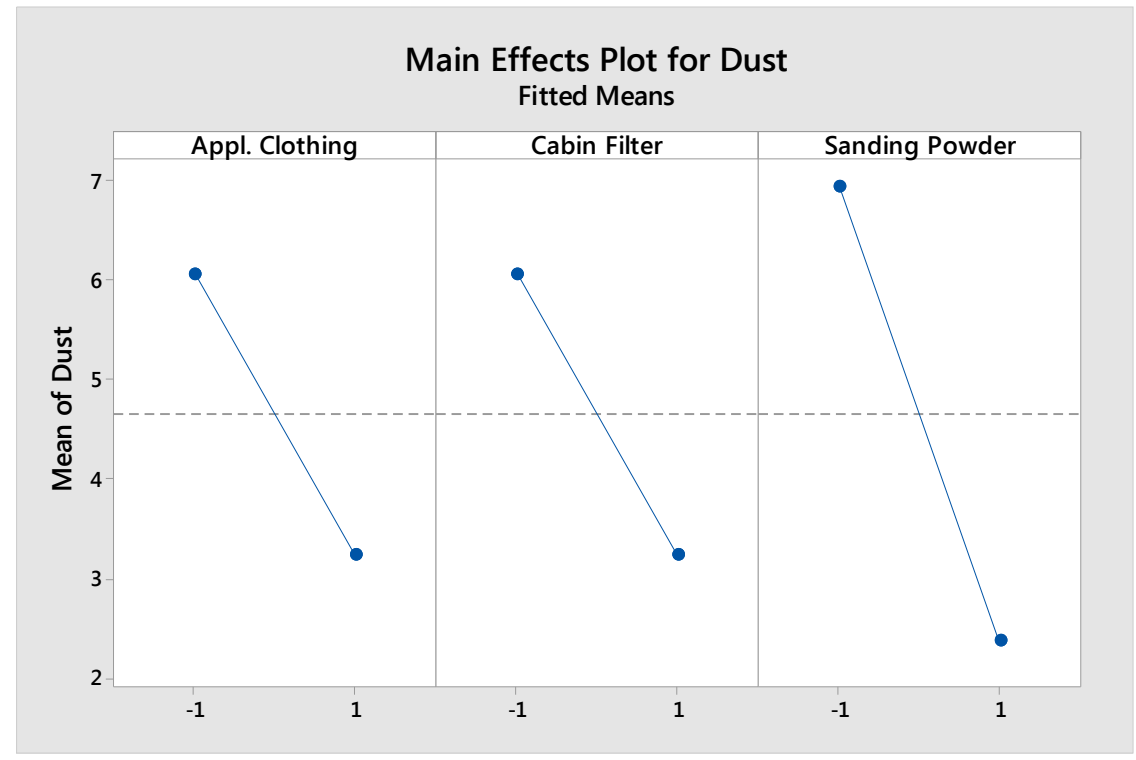


Figure 15 Interaction plot for dust error type (after) (see online version for colours)

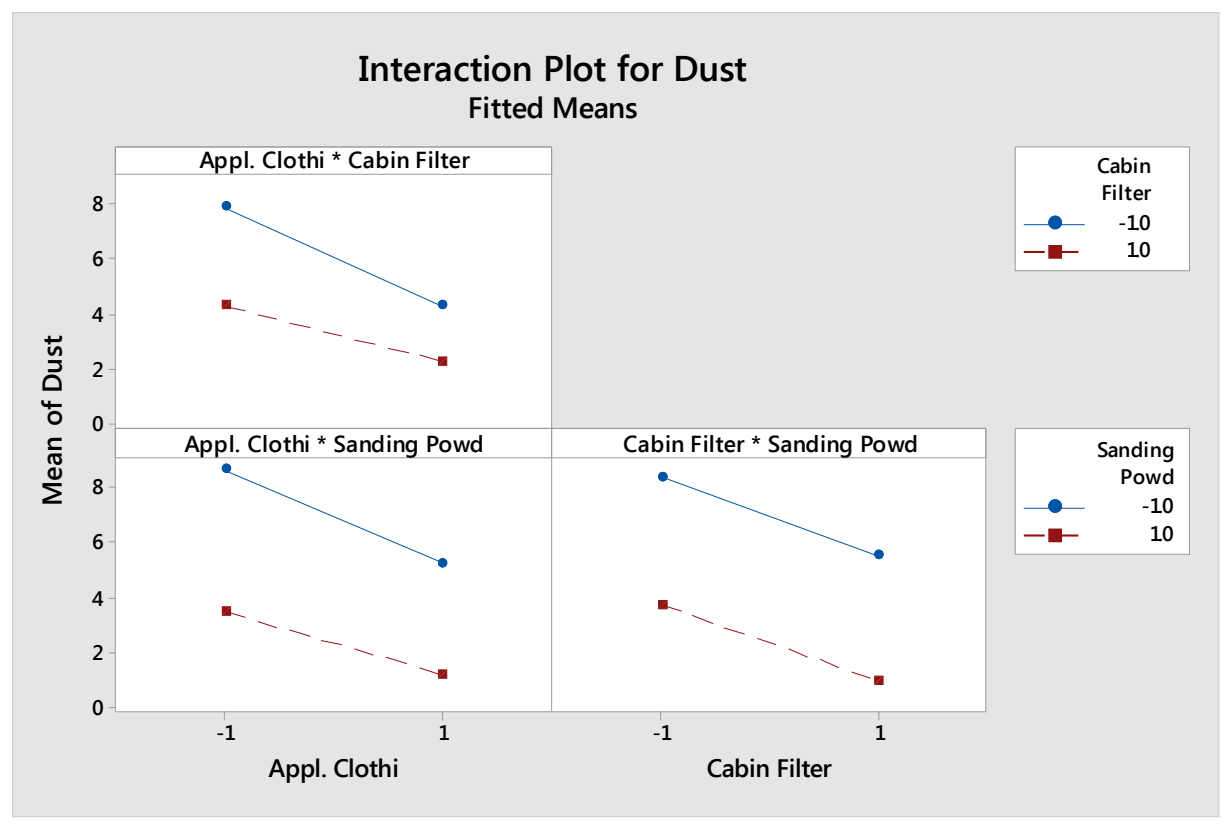

Table 12 Minitab analyses ANOVA values for dust error type (after)

\begin{tabular}{lccccc}
\hline Source & $D F$ & Adj SS & Adj MS & F-Value & P-Value \\
\hline Model & 7 & 303.469 & 43.353 & 52.68 & 0.000 \\
Linear & 3 & 293.094 & 97.698 & 118.72 & 0.000 \\
$\begin{array}{l}\text { Application } \\
\text { Clothes }\end{array}$ & 1 & 63.281 & 63.281 & 76.90 & 0.000 \\
Cabin Filter & 1 & 63.281 & 63.281 & 76.90 & 0.000 \\
$\begin{array}{l}\text { Sanding Dust } \\
\text { on the Surface }\end{array}$ & 1 & 166.531 & 166.531 & 202.37 & 0.000 \\
$\begin{array}{l}\text { 2-Way } \\
\text { Interactions }\end{array}$ & 3 & 7.844 & 2.615 & 3.18 & 0.042 \\
$\begin{array}{l}\text { Application } \\
\text { Clothes* }\end{array}$ & 1 & 5.281 & 5.281 & 6.42 & 0.018 \\
$\begin{array}{l}\text { Cabin Filter } \\
\begin{array}{l}\text { Application } \\
\text { Clothes* }\end{array}\end{array}$ & 1 & 2.531 & 2.531 & 3.08 & 0.092 \\
$\begin{array}{l}\text { Sanding Dust } \\
\text { on the Surface }\end{array}$ & & & & & \\
$\begin{array}{l}\text { Cabin } \\
\text { Filter*Sanding }\end{array}$ & 1 & 0.031 & 0.031 & 0.04 & 0.847 \\
$\begin{array}{l}\text { Dust on the } \\
\text { Surface }\end{array}$ & & & & & \\
\hline
\end{tabular}


Table 12 Minitab analyses ANOVA values for dust error type (after) (continued)

\begin{tabular}{lccccc}
\hline Source & DF & Adj SS & Adj MS & F-Value & P-Value \\
\hline 3-Way & 1 & 2.531 & 2.531 & 3.08 & 0.092 \\
$\begin{array}{l}\text { Interactions } \\
\text { Application }\end{array}$ & 1 & 2.531 & 2.531 & 3.08 & 0.092 \\
$\begin{array}{l}\text { Clothes*Cabin } \\
\text { Filter*Sanding }\end{array}$ & & & & \\
$\begin{array}{l}\text { Dust on the } \\
\text { Surface }\end{array}$ & & & & \\
Error & 24 & 19.75 & 0.823 & & \\
Total & 31 & 323.219 & & & \\
\hline
\end{tabular}

\section{Conclusions and recommendations}

In this study, the QFD, the FMEA, and the experimental design applications were conducted on the processes involved in producing passenger-vehicle bumpers. After a detailed analysis, the processes of injection, painting, and assembly were targeted as they were the most troublesome processes. In the beginning, by applying the QFD, 25 customer expectations were observed to be associated with 25 quality characteristics in the matrix structure, and the weighted value of each characteristic was calculated according to their degree of difficulty, thus enabling a determination of quality characteristics and customer expectations. Because the first three characteristics with the highest weighted value were the applications of primer, paint, and varnish, the priority for improvement was determined to be paint, although all processes were improved. Moreover, a comparison was made with one rival company in the QFD structure. The FMEA study was applied to all related processes, beginning with the process having the highest weighted value in the QFD application. In the FMEA application, the RPN value, including the multiplication of intensity, detectability, and probability values, was calculated using a 10-point scale. Actions for improvement were implemented primarily for the characteristics with high RPN values, and the corresponding RPN values decreased after applying the improvements. For example, the pre improvement RPN value was 210 for the problem of the presence of dirt/foreign matter during the painting process; whereas, the post improvement RPN was calculated to be 70 . A significant decline in the RPN values indicated that the improvement actions were effective. Fiftyfive failure types were examined in the FMEA application, and 35 of these failure types were improved. Especially the processes of injection, painting, and assembly were improved.

After the QFD and FMEA studies, the problem of dust/dirt on the produced bumpers was targeted, and experimental design was set up to improve the three most important processes. All quality characteristics (missing injection, paint sagging, crater, the problem of dirt on the surface, dust, version error, missing installation, friction - scratch - pulse) of the process were improved thanks to experimental design application. Better application clothes and appropriate type for cabin filters were determined, and the use of air guns before the painting process highly recovered the dust problem. 
In future studies, this study can be used for different production processes in various sectors. Comparing the results in the various sectors, the tools used in this study can also be improved.

\section{Acknowledgements}

The author would like to thank Mrs. Merve Günaydın Aşçı for her valuable help in the data collection process and in preparation of some of the tables and graphics presented in this manuscript.

\section{References}

Akao, Y. (1997) 'QFD: past, present, and future', Paper Presented at the International Symposium on QFD 97, Asahi University, Linköping.

Akman, G. and Özkan, C. (2011) 'Solving adhesion problem in metal sheet manufacturing with design of experiments', Dogus University Journal, Vol. 12, No. 2, pp.187-199.

Anawa, E.M. and Olabi, A.G. (2008) 'Using Taguchi method to optimize welding pool of dissimilar laser-welded components', Optics and Laser Technology, Vol. 40, pp.379-388.

Ardıç, K., Çevik, O. and Göktaş, Ş. (2008) 'Quality function deployment (An application at GOP University)', Journal of Academic Inquiries, Vol. 3, No. 2, pp.111-139.

Asadabadi, M.R. (2017) 'A customer based supplier selection process that combines quality function deployment, the analytic network process and a Markov chain', European Journal of Operational Research, Vol. 263, pp.1049-1062.

Bahloul, R., Mkaddem, A., Santo, P.D. and Potiron, A. (2006) 'Sheet metal bending optimisation using response surface method, numerical simulation and design of experiments', International Journal of Mechanical Sciences, Vol. 48, pp.991-1003.

Bergquist, K. and Abeysekera, J. (1996) 'Quality function deployment (QFD)-a means for developing usable products', International Journal of Industrial Ergonomics, Vol. 18, No. 4, pp.269-275.

Beyenea, A.T., Korichob, E.G., Belingardib, G. and Martoranac, B. (2014) 'Design and manufacturing issues in the development of lightweight solution for a vehicle frontal bumper', Procedia Engineering, Vol. 88, pp.78-84, doi: 10.1016/j. proeng.2014.11.129.

Breyfogle, F.W. (2003) Implementing Six Sigma: Smarter Solutions Using Statistical Methods, 2nd ed., John Wiley \& Sons, Inc., New Jersey.

Cheng, W.T., Li, H.C. and Huang, C.N. (2008) 'Simulation and optimization of silicon thermal CVD through CFD integrating Taguchi method', Chemical Engineering Journal, Vol. 137, pp.603-613.

Chin, K.S., Yang, Q., Chan, C.Y.P., Tsui, K.L. and Li, Y. (2019) 'Identifying passengers' needs in cabin interiors of high-speed rails in China using quality function deployment for improving passenger satisfaction', Transportation Research Part A, Vol. 119, pp.326-342.

Costa, A.I.A., Dekker, M. and Jongen, W.M.F. (2001) 'Quality function deployment in the food industry: a review', Trends in Food Science and Technology, Vol. 11, pp.306-314.

Delice Kılıç, E. and Güngör, Z. (2008) 'A new approach for quality function deployment: an application', Akademik Bilişim Conference, 30 January-01 February, Çanakkale Onsekiz Mart University.

Dixon, D., Eatock, J., Meenan, B.J. and Morgan, M. (2006) 'Application of design of experiment (DOE) techniques to process validation in medical device manufacture', Journal of Validation Technology, Vol. 12, No. 2, pp.92-100. 
Fan, S., Xiong, J., Xu, T., Chen, S.Y. and Zhang, W. (2017) 'QFD design of machine-made sand based on independent/Decomposition axiom', Procedia Engineering, Vol. 174, pp.442-448.

Gilchrist, W. (1993) 'Modelling failure modes and effects analysis', International Journal of Quality and Reliability Management, Vol. 10, No. 5, pp.16-23.

Govers, C.P.M. (2001) 'QFD not just a tool but a way of quality management', Int. J. Production Economics, Vol. 69, pp.151-159.

Guo, Q., Sheng, K., Wang, Z., Zhang, X., Yang, H. and Miao, R. (2017) 'Research on element importance of shafting installation based on QFD and FMEA', Procedia Engineering, Vol. 174, pp.677-685.

Hamzaçebi, C. and Kutay, F. (2003) 'Taguchi method: an application', Teknoloji, Vol. 3, No. 4, pp.7-17.

Kim, J., Miller, B., Siddiqui, M.S., Movsas, B. and Glide-Hurst, C. (2019) 'FMEA of MR-only treatment planning in the pelvis', Advances in Radiation Oncology, Vol. 4, pp.168-176.

Kwak, Y.H. and Anbari, F.T. (2006) 'Benefits, obstacles, and future of six sigma approach', Technovation, Vol. 26, pp.708-715.

Lai, X., Tan, K.C. and Xie, M. (2007) 'Optimizing product design using quantitative quality function deployment: a case study', Quality and Reliability Engineering International, Vol. 23, pp.45-57.

Lazić, Z.R. (2004) Design of Experiments in Chemical Engineering: A Practical Guide, WILEY$\mathrm{VCH}$, Weinheim.

Lijesh, K.P., Muzakkir, S.M. and Hirani, H. (2016) 'Failure mode and effect analysis of passive magnetic bearing', Engineering Failure Analysis, Vol. 62, pp.1-20.

Liu, H. and Cheng, H. (2016) 'An improved grey quality function deployment approach using the grey TRIZ technique', Computers and Industrial Engineering, Vol. 92, pp.57-71, doi: $10.1016 /$ j. cie.2015.11.003.

Liu, Y., Kong, Z. and Zhang, Q. (2018) 'Failure modes and effects analysis (FMEA) for the security of the supply chain system of the gas station in China', Ecotoxicology and Environmental Safety, Vol. 164, pp.325-330.

Lunani, M., Nair, V.N. and Wasserman, G.S. (1997) 'Graphical methods for robust design with dynamic characteristics', Journal of Quality Technology, Vol. 29, No. 3, pp.327-338.

Lunau, S., Staudter, C., Mollenhauer, J.P., Meran, R., Roenpage, O., Hugo, C.V. and Hamalides, A. (2009) Design for Six Sigma + Lean Toolset, Springer, Germany.

Mazur, G.H. (1993) 'QFD for service industries from voice of customer to task deployment', The Fifth Symposium on Quality Function Deployment, 20-22 June, Novi, Michigan.

Montgomery, D.C. (2013) Design and Analysis of Experiments, 8th ed., John Wiley and Sons Inc., USA.

Oudjene, M. and Ben-Ayed, L. (2008) 'On the parametrical study of clinch joining of metallic sheets using the Taguchi method', Engineering Structures, Vol. 30, pp.1782-1788.

Partovi, F.Y. and Corredoira, R.A. (2002) 'Quality function deployment for the good of soccer', European Journal of Operational Research, Vol. 137, pp.642-656.

Peeters, J.F.W., Basten, R.J.I. and Tinga, T. (2018) 'Improving failure analysis efficiency by combining FTA and FMEA in a recursive manner', Reliability Engineering and System Safety, Vol. 172, pp.36-44.

Popoff, A. and Millet, D. (2017) 'Sustainable life cycle design using constraint satisfaction problems and quality function deployment', Procedia CIRP, Vol. 61, pp.75-80.

Rojas, C.R., Welsh, J.S., Goodwin, G.C. and Feuer, A. (2007) 'Robust optimal experiment design for system identification', Automatica, Vol. 43, pp.993-1008.

Rosa, J.L., Robin, A., Silva, M.B., Baldan, C.A. and Peres, M.P. (2009) 'Electrodeposition of copper on titanium wires: Taguchi experimental design approach', Journal of Materials Processing Technology, Vol. 209, pp.1181-1188. 
Savaşkan, M., Taptık, Y. and Ürgen, M. (2004) 'Performance optimization of drill bits using design of experiments', Itüdergisi, Serie D: Engineering, Vol. 3, No. 6, pp.117-128.

Setiawan, T.H., Adryfan, B. and Putra, C.A. (2017) 'Risk analysis and priority determination of risk prevention using failure mode and effect analysis method in the manufacturing process of hollow core slab', Procedia Engineering, Vol. 171, pp.874-881.

Sohn, S.Y. (1999) 'Quality function deployment applied to local traffic accident reduction', Accident Analysis and Prevention, Vol. 31, No. 6, pp.751-761.

Vandenbrande, W.W. (1998) 'How to use FMEA to reduce the size of your quality toolbox', Quality Progress, Vol. 31, No. 11, pp.97-100.

Wang, C.H. (2017) 'Incorporating the concept of systematic innovation into quality function deployment for developing multi-functional smart phones', Computers and Industrial Engineering, Vol. 107, pp.367-375.

Yang, C., Shen, W., Chen, Q. and Gunay, B. (2018) 'A practical solution for HVAC prognostics: failure mode and effects analysis in building maintenance', Journal of Building Engineering, Vol. 15, pp.26-32.

Yang, K. and El-Haik, B. (2003) Design for Six Sigma: A Roadmap for Product Development, The McGraw-Hill Companies, USA.

Yang, Q., Chin, K.S. and Li, Y.L. (2018) 'A quality function deployment-based framework for the risk management of hazardous material transportation process', Journal of Loss Prevention in the Process Industries, Vol. 52, pp.81-92.

Yang, W.H. and Tarng, Y.S. (1998) 'Design optimization of cutting parameters for turning operations based on the Taguchi method', Journal of Materials Processing Technology, Vol. 84, pp.122-129. 